\title{
Elective use of an uncuffed small-bore cricothyrotomy tube with balloon occlusion of the subglottic airway
}

\section{Utilisation d'une sonde de cricothyrotomie à petit calibre sans ballonnet avec occlusion sous-glottique par ballonnet en chirurgie réglée}

\author{
Takashi Suzuki, MD, PhD • Haruo Ikeda, MD, PhD • Taito Iwamoto, MD • \\ Hitomi Sano, MD • Megumi Hashimoto, MD, PhD • Katsunori Oe, MD, PhD • \\ Haruhiro Inoue, MD, PhD • Kazuyuki Serada, MD, PhD
}

Received: 27 May 2013/Accepted: 10 October 2013/Published online: 25 October 2013

(C) Canadian Anesthesiologists' Society 2013

\begin{abstract}
Purpose To conduct a qualitative observational study on positive pressure ventilation through a percutaneous uncuffed small-bore cricothyrotomy tube with balloon occlusion of the subglottic airway to minimize supraglottic leak.

Clinical features Ten consecutive procedures were performed in the nine men enrolled in this study. The demographics of the participants were: aged 50-73 yr, weight 48-87 kg, American Society of Anesthesiologists class I-II, and scheduled for endoscopic submucosal dissection via flexible endoscopy for en bloc resection of superficial meso- and hypopharyngeal cancer. The airway was initially secured with a supraglottic airway (SGA) under sevoflurane-based anesthesia, and a cricothyrotomy was then performed using a Portex ${ }^{\circledR}$ Minitrach II uncuffed

Author contributions Takashi Suzuki, the principal investigator, conceived the study design, supervised data collection, and drafted the manuscript. Haruo Ikeda was involved in the design of the study. Taito Iwamoto, Hitomi Sano, and Megumi Hashimoto were involved in data acquisition. Megumi Hashimoto and Katsunori Oe provided critical input into the interpretation of studies and the early versions of the manuscript. Haruhiro Inoue and Kazuyuki Serada made intellectual contributions to the manuscript.
\end{abstract}

T. Suzuki, MD, PhD (ه) · T. Iwamoto, MD - H. Sano, MD

M. Hashimoto, MD, PhD · K. Oe, MD, PhD

K. Serada, MD, PhD

Department of Anesthesia, Showa University Northern

Yokohama Hospital, 35-1 Chigasaki-Chuo, Tsuzuki-ku,

Yokohama 224-8503, Japan

e-mail: tksuzuki@med.showa-u.ac.jp

H. Ikeda, MD, PhD · H. Inoue, MD, PhD

Digestive Disease Center, Showa University Northern

Yokohama Hospital, Yokohama, Japan cricothyrotomy tube (4-mm internal diameter). Following SGA removal, a Coopdech ${ }^{\circledR}$ bronchial blocker was orally or nasally inserted, and the balloon was inflated to occlude the trachea immediately beneath the glottis. The ventilator setting was initially based on observation of chest motion and end-tidal carbon dioxide tension and then readjusted according to arterial blood gas levels. All procedures were completed within a median time of 149 min. Effective ventilation was achieved in all patients despite mild hypercapnia $\left(\mathrm{PaCO}_{2}\right.$ of $58 \mathrm{mmHg}$ at maximum) in some patients. $\mathrm{SpO}_{2}$ levels were maintained at $\geq 98 \%$.

Conclusion This technique provides effective intraoperative ventilation and easy endoscopic access, and it countermeasures against the likely complication of postoperative laryngeal edema. Moreover, there is no need for conventional tracheostomy or prolonged intubation. This approach establishes a curative and less invasive pharyngeal cancer therapy. Certain adverse outcomes can be avoided, including impaired speech and swallowing, possible delayed closure of the stoma, or a compromised cosmetic outcome.

Résumé

Objectif Réaliser une étude observationnelle qualitative sur la ventilation en pression positive via une sonde percutanée de cricothyrotomie à petit calibre sans ballonnet avec occlusion sous-glottique par ballonnet afin de minimiser les fuites supra-glottiques.

Éléments cliniques Dix interventions traditionnelles ont été réalisées auprès des neuf hommes participant à cette étude. Les données démographiques des participants étaient les suivantes: âge 50-73 ans, poids 48-87 kg, classe I-II selon l'American Society of Anesthesiologists, et 
devant subir une dissection sous-muqueuse endoscopique par endoscopie souple pour une résection en bloc de cancers méso- et hypopharyngés superficiels. Les voies aériennes ont d'abord été maintenues à l'aide d'un dispositif supraglottique sous une anesthésie à base de sévoflurane, et une cricothyrotomie a ensuite été réalisée à l'aide d'une sonde de cricothyrotomie sans ballonnet Portex $^{\circledR}$ Minitrach II (diamètre interne $4 \mathrm{~mm}$ ). Après retrait $d u$ dispositif supraglottique, un bloqueur bronchique Coopdech ${ }^{\circledR}$ a été inséré par voie orale ou nasale, et le ballonnet a été gonflé afin de bloquer la trachée immédiatement sous la glotte. Le réglage du ventilateur était d'abord fondé sur l'observation des mouvements du thorax et la tension de dioxyde de carbone télé-expiratoire, puis réajusté en fonction des gaz sanguins artériels. Toutes les interventions ont été réalisées dans un temps moyen de $149 \mathrm{~min}$. Une ventilation efficace a été mise en place chez tous les patients malgré une légère hypercapnie $\left(\mathrm{PaCO}_{2}\right.$ de $58 \mathrm{mmHg}$ au maximum) chez quelques patients. Les niveaux de $\mathrm{SpO}_{2}$ ont été maintenus à $\geq 98 \%$.

Conclusion Cette technique permet d'obtenir une ventilation peropératoire efficace et offre un accès endoscopique facile; en outre, elle constitue une bonne contre-mesure contre la complication probable d'œè̀me laryngé postopératoire. De plus, la trachéostomie traditionnelle et l'intubation prolongée ne sont pas nécessaires. Cette approche constitue un traitement du cancer pharyngé curatif et moins effractif. Certains effets secondaires défavorables, notamment une élocution et une déglutition difficiles, une fermeture possiblement retardée de la stomie ou un résultat cosmétique décevant, peuvent être évités.

Recent advances in gastrointestinal endoscopy enable en bloc resection of superficial pharyngeal cancers using a novel technique, namely, endoscopic submucosal dissection (ESD), ${ }^{1}$ under general anesthesia. ${ }^{2}$ In our institution, when the arytenoids are involved in lesions, surgical tracheostomy is often conducted before the procedure as an endotracheal tube (ETT) might impair endoscopic manipulation. In addition, the tracheostomy tube is beneficial for postoperative airway control in the likely event of potentially life-threatening laryngeal edema.

During recovery, however, the presence of a tracheostomy tube may interfere with patients' speech and swallowing, ${ }^{3}$ and possibly lead to delayed closure of the stoma or compromised cosmetic outcome. ${ }^{4}$ Our solution to these drawbacks from tracheostomy was to employ a percutaneous small-bore cricothyrotomy tube. Previous model lung studies showed that uncuffed smallbore devices with open upper airways yielded ineffective ventilation, whereas acceptable ventilation can be achieved by occlusion of the upper airway. ${ }^{5-7}$

Thus, the purpose of this study was to examine the feasibility of controlled ventilation for cricothyrotomy via an uncuffed small-bore tube, together with an orally or nasally inserted subglottic balloon to minimize supraglottic leak.

\section{Methods}

This study was approved by the Institutional Review Board of Showa University Northern Yokohama Hospital in July 2011 (approval number 1106-4). We estimated that a convenience sample of ten procedures was needed for evaluation in this qualitative observational study. Written informed consent was obtained from each patient for participation in the study. Inclusion criteria were patients diagnosed with superficial cancer of the meso- or hypopharynx and scheduled for en bloc resection using ESD. Exclusion criteria were cases in which ESD was considered achievable under endotracheal intubation without interference with endoscopic manipulation as well as cases with a low risk of postoperative laryngeal edema judging from the size and location of lesions. Patients with a history of tracheal disease, permanent tracheostomy, body mass index $>35 \mathrm{~kg} \cdot \mathrm{m}^{-2}$, and respiratory compromise were also excluded. No premedication was administered. Standard monitors were applied in the operating room.

With the patient in the supine position, the airway was initially secured with a supraglottic airway (SGA), such as LMA-ProSeal $^{\text {TM }}$ (Intavent-Orthofix, Maidenhead, UK) or i-Gel ${ }^{\mathrm{TM}}$ (Intersurgical, Wokingham, UK), according to the anesthesiologist's preference. A percutaneous cricothyrotomy was then performed by the conducting anesthesiologist using a Portex ${ }^{\circledR}$ Minitrach II (MT) (Smiths Medical International Ltd., Hythe, UK) uncuffed tube with a 4-mm internal diameter (ID). The Seldinger technique was used under the guidance of a fibreoptic bronchoscope introduced via the SGA. Thereafter, ventilation was commenced through the MT.

Anesthesia was induced with propofol and fentanyl and maintained with sevoflurane and remifentanil. Rocuronium was administered mainly to prevent coughing or laryngospasm during manipulation of the fibreoptic bronchoscope and insertion of the MT. In some cases, subsequent rocuronium doses were given intermittently according to the anesthesiologists' judgment.

Following SGA removal, a specially designed surgical laryngoscope ${ }^{8}$ (Nagashima Medical Instrumental Co., Ltd., Tokyo, Japan) was used to expose the glottis. Depending on the location of the lesion, a bronchial blocker (BB) 
(Coopdech $^{\circledR}$ endobronchial blocker with spindle-type cuff, Daiken, Osaka, Japan) ${ }^{9}$ was inserted orally or nasally so as not to interfere with the endoscopy. The balloon attached to the angulated tip of the BB was lodged immediately beneath the glottis under direct visualization through the esophagogastroduodeno-scope, directed backwards using axis rotation of the shaft of the $\mathrm{BB}$, and inflated with air to minimize air leak. The proximal part of the $\mathrm{BB}$ that protruded from the mouth or nostril was securely taped to the patient's face (Fig. 1).

The procedure commenced after insertion of a radial artery catheter. Arterial blood gas analyses were performed immediately before the procedure (baseline) and every $30 \mathrm{~min}$ thereafter. Pressure-controlled ventilation (PCV) without positive end-expiratory pressure was applied. Peak inspiratory pressure and respiratory rate were initially adjusted according to observation of chest motion and endtidal carbon dioxide tension obtained from a side-stream capnometer, and then, they were readjusted according to baseline blood gas levels. A trial-and-error approach with ventilator resetting and refinement of $\mathrm{BB}$ status was used to maintain normocapnia. Inspired oxygen fraction was adjusted to maintain the $\mathrm{SpO}_{2}$ at $\geq 98 \%$.

For adequate visualization of the surgical site, carbon dioxide insufflation and irrigating fluids were delivered through the channels of the endoscope. The submucosal layer of the lesion was dissected using endoscopic electrocautery knives. During the procedure, a $10 \mathrm{Fr}$ nasopharyngeal catheter for continuous suctioning was

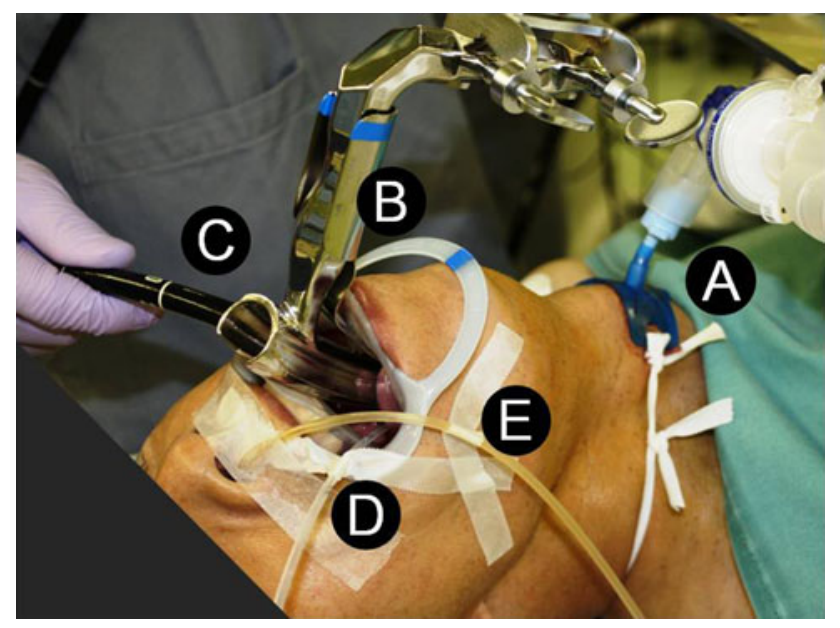

Fig. 1 Instrumental setup for therapeutic endoscopy of the pharynx. Instrumental setup for endoscopic submucosal dissection of superficial pharyngeal cancer under controlled ventilation through a Portex ${ }^{\circledR}$ Minitrach II (uncuffed cricothyrotomy tube with internal diameter of 4-mm) is shown. $\mathrm{A}=$ Minitrach II; $\mathrm{B}=$ surgical laryngoscope; $\mathrm{C}=$ fibreoptic esophagogastroduodeno-scope for intervention; $\mathrm{D}=$ orally inserted Coopdech ${ }^{\circledR}$ bronchial blocker for subglottic tracheal occlusion; $\mathrm{E}=$ nasopharyngeal catheter $(10 \mathrm{Fr}$ ) for continuous suctioning placed in the oropharynx to prevent aspiration. The endoscopic view was displayed on a monitor, allowing the anesthesiologist to assess the status of the BB (e.g., dislodgement, shrinkage, or interference with the endoscope).

All participants were scheduled to return to the ward postoperatively. Repeated palpation of the chest was performed to check for subcutaneous emphysema. Postoperatively, the MT was left in situ for transtracheal suctioning and airway control during possible or actual laryngeal edema. Chest $x$-ray studies were performed after the procedures and the radiographs were examined by radiologists.

\section{Results}

Thirteen procedures in 11 consenting patients were screened. Three procedures in two patients were excluded from the study since they were performed under endotracheal intubation after considering the size and location of the lesions. Hence, ten procedures in nine enrolled patients were evaluated in this study. Each patient's characteristics and procedure-related data are listed in the Table.

It was often necessary to adjust the insertion depth of the $\mathrm{BB}$, reposition the balloon, and add air to the balloon in a trial-and-error manner before and during the procedure in order to minimize supraglottic leakage, prevent obstruction of the tip of the cricothyrotomy cannula with the BB, and establish continuous monitoring of capnography.

The time-course of changes in $\mathrm{PaCO}_{2}$ are shown in Fig. 2. The $\mathrm{PaCO}_{2}$ values mostly indicated normocapnia or mild hypocapnia, although they exceeded $50 \mathrm{mmHg}$ in two procedures. In one procedure (case 1a), $\mathrm{PaCO}_{2}$ varied from $48-58 \mathrm{mmHg}$, but at a second procedure (case $1 \mathrm{~b}$ ) in the same patient undertaken eight months later, mild hypocapnia was maintained. In another procedure (case 3 ), hypercapnia resolved during the surgical course.

Peak inspiratory pressures and respiratory rates during the procedures varied widely from $18-60 \mathrm{~cm} \mathrm{H}_{2} \mathrm{O}$ and from $12-20$ breaths $\cdot \min ^{-1}$, respectively, primarily depending on the amount of the leak that developed. $\mathrm{SpO}_{2}$ values were maintained at $\geq 98 \%$ in all patients. Intraoperative hemodynamics remained stable and emergence from anesthesia was uneventful. Postoperatively, all patients were successfully returned to ordinary wards.

Postoperative chest $x$-ray studies revealed no new infiltrations. No notable anesthesia-related adverse events (e.g., subcutaneous emphysema, pneumothorax, mediastinal emphysema, apparent evidence of regurgitation, bleeding requiring surgical hemostasis, or MT malplacement) were recognized. A representative endoscopic view is shown in Fig. 3. All MTs were removed by the fourth postoperative day. 


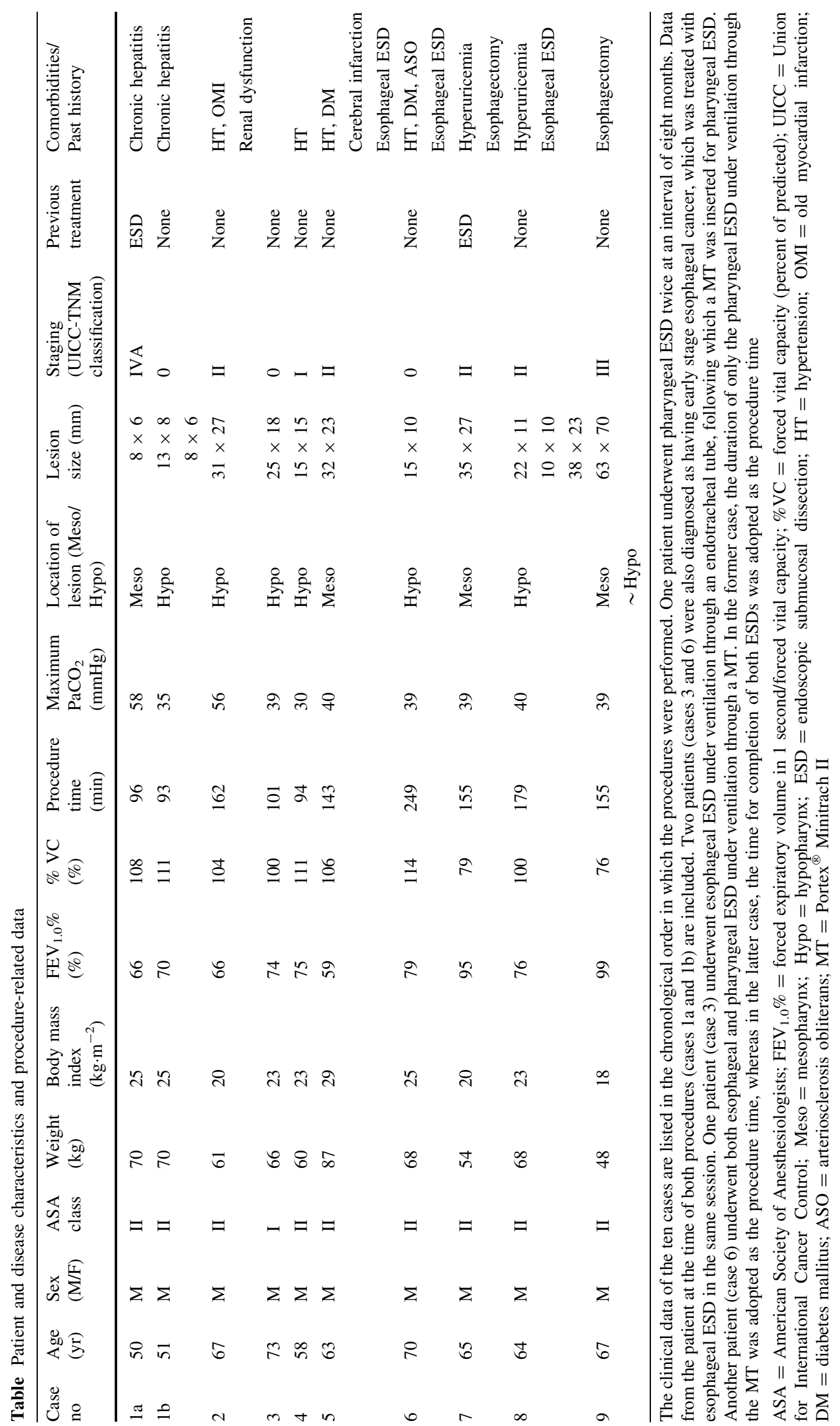




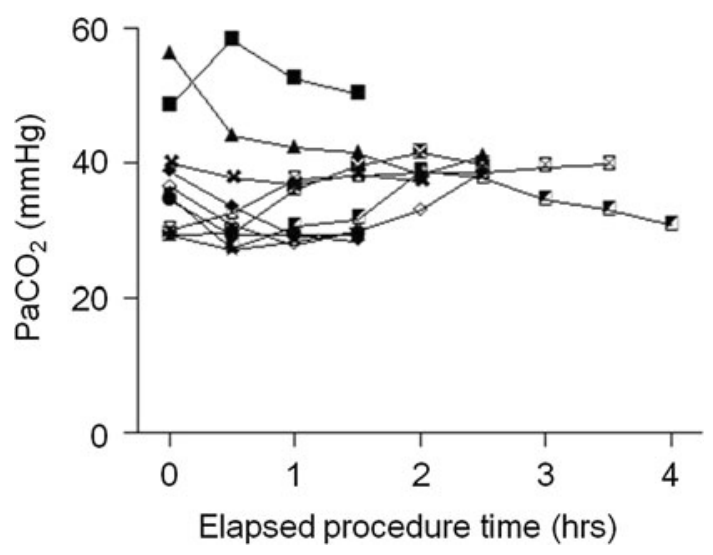

Fig. 2 Time courses of $\mathrm{PaCO}_{2}$ during the procedure. Graph showing individual time courses of $\mathrm{PaCO}_{2}$ during endoscopic submucosal dissection of the pharynx under controlled ventilation through a Portex ${ }^{\circledR}$ Minitrach II (uncuffed cricothyrotomy tube with internal diameter of 4-mm) together with an orally or nasally inserted Coopdech ${ }^{\circledR}$ bronchial blocker inflated beneath the glottis to minimize air leakage into the oropharynx

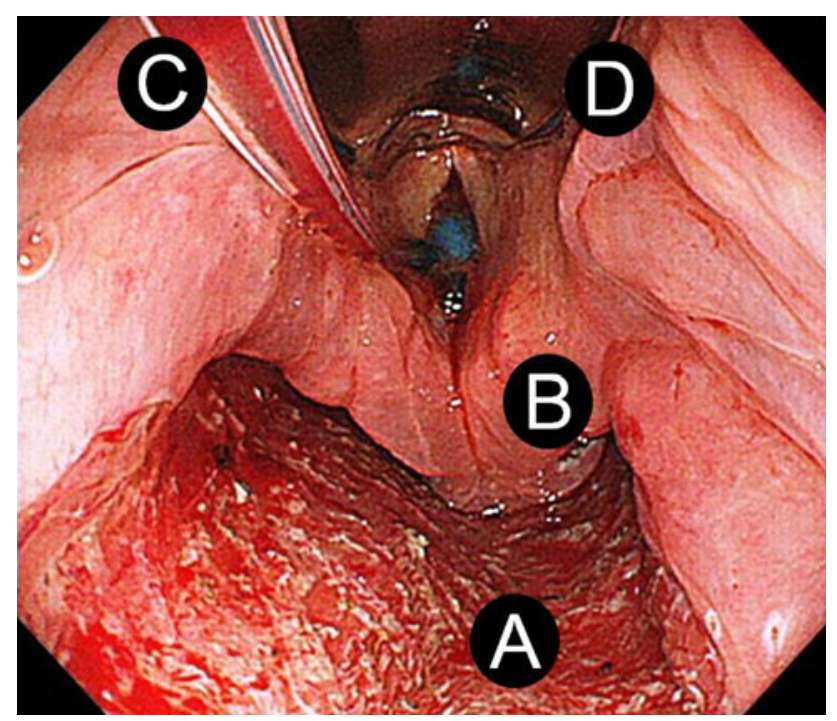

Fig. 3 Endoscopic view of the pharyngolarynx. A representative endoscopic view of the pharyngolarynx is presented immediately after completion of the endoscopic submucosal dissection for superficial pharyngeal cancer. (A) An area of mucosa surrounding the lesion, which was located at the posterior wall of the pharynx, was removed; (B) Swollen aryepiglottic folds; (C) the shaft of the Coopdech $^{\circledR}$ bronchial blocker anchored immediately beneath the glottis; (D) the tip of the blade of the surgical laryngoscope used to expose the glottis

\section{Discussion}

We conducted successful airway and anesthetic management in nine patients undergoing pharyngeal ESD. Ventilation was controlled through a MT together with an orally or nasally inserted BB anchored beneath the glottis to minimize supraglottic leak. Continuous oropharyngeal drainage was applied in tandem using a nasopharyngeal catheter.

The worldwide annual incidences of pharyngeal carcinoma and associated deaths in 2008 were estimated to be 135,000 and 95,000 , respectively. ${ }^{10}$ This high mortality could be explained partly by the difficulty in early diagnosis. Modern narrow band imaging and magnification endoscopy facilitate detection of earlystage pharyngeal cancer. ${ }^{11}$ This can be treated with ESD, as has been described in several case series from Japan. In two different series, tracheal extubation was not performed on the day of the procedure in 61 of $93(67 \%)$ patients and in 22 of $51(43 \%)$ patients. ${ }^{12,13}$ In another series, four of 21 (19\%) patients underwent a tracheostomy postoperatively. ${ }^{14}$ These reports disclosed that invasive or bothersome airway management was employed in patients who underwent a procedure that was supposedly a novel therapeutic option with the benefit of minimal invasiveness.

Cricothyrotomy (cricothyroidotomy), also known as minitracheotomy (minitracheostomy), can be percutaneously performed using a MT or competitive products. The Portex ${ }^{\circledR}$ Minitrach II, originally introduced for tracheobronchial suction, ${ }^{15}$ is currently recognized as an emergency tool for "can't intubate can't ventilate" situations. ${ }^{16}$

In an earlier study regarding lung ventilation through cricothyrotomy using a model lung, PCV via a MT yielded $40 \%$ of ventilatory volume of the values using an 8-mm ID ETT. This result was yielded at varying degrees of lung compliance and in the absence of upper airway leak. When a certain degree of leak existed, these values further decreased to $30 \%$ of control values using the ETT. ${ }^{5}$ In a subsequent study, an uncuffed 6-mm ID Melker ${ }^{\circledR}$ tube (Cook, Bloomington, IN, USA) provided effective ventilation irrespective of upper airway resistance, whereas the uncuffed 4-mm ID Quicktrach ${ }^{\circledR}$ I (VBM Medizintechnik, Tuttlingen, Germany) performed effectively only with increased upper airway resistance. ${ }^{6}$

Recently, cuffed devices for emergency ventilation have been marketed, ${ }^{17,18}$ although none are currently commercially available in Japan. In a more recent study, both cuffed and uncuffed devices varying in ID from 4-6 $\mathrm{mm}$ were examined using a model lung to assess whether effective ventilation could be obtained. Effective ventilation was defined as a tidal volume of $\geq 300 \mathrm{~mL}$ delivered by volume control ventilation in an ordinary setting with normal lung compliance and airway resistance. $^{7}$ Reportedly, uncuffed devices, including a 6-mm ID Melker ${ }^{\circledR}$, yielded ineffective ventilation in the presence of a large leak, whereas, not surprisingly, every cuffed device produced satisfactory results irrespective of 
the amount of leak. The uncuffed 4-mm ID Quicktrach ${ }^{\circledR}$ I was acceptable for controlled ventilation with little to no leakage, allowing spontaneous ventilation without excessive negative inspiratory pressure even with complete obstruction. Our study clinically validated the adequacy of controlled ventilation through a 4-mm ID tube- which is probably the cut-off value for effective ventilation - based on the observed $\mathrm{PaCO}_{2}$ level in a noncritically ill population. The observed moderate hypercapnia was transient or did not recur at a second procedure. Mere technical refinement of BB positioning to reduce the leakage seemed to improve ventilation.

Even when cuffed devices are available, the MT still provides some benefits. For instance, the cuffed 4-mm ID Quicktrach $^{\circledR}$ II (VBM Medizintechnik) is 7.3-mm in maximum outer diameter (OD), whereas the MT has an OD of $5.4 \mathrm{~mm}^{19}$ The recently introduced cuffed Melker ${ }^{\circledR}$ is $5 \mathrm{~mm}$ in ID and has a 7.2-mm maximum OD. Although the differences in OD between these devices and the MT may be small, the smaller OD would be beneficial for the patients' quality of recovery. Additionally, the Quicktrach ${ }^{\circledR}$ II can be placed as a cannula over the needle, which reportedly requires less time to perform but is less reliable than the Seldinger technique ${ }^{17,18,20}$ employed with the MT and Melker ${ }^{\circledR}$ tubes.

The optimal ventilator setting during ventilation through a MT is a real concern, since a marked drop in pressure along the tube is inevitable. Findings from the abovementioned study indirectly suggest that about a threefold higher inspiratory pressure is needed in PCV to obtain adequate ventilation when the MT is utilized instead of a standard ETT. ${ }^{5}$ Although placement of a heat and moisture exchanger and an elbow could influence flow resistance, ${ }^{21}$ this estimation was in fair agreement with actual adjusted ventilator settings.

Measures to counter the leak associated with use of uncuffed cricothyrotomy and tracheostomy tubes have generated much interest. ${ }^{22-24}$ In our experience, once the MT is placed, it is beneficial to use an SGA with occlusion of the $15-\mathrm{mm}$ connector until insertion of the surgical laryngoscope. Simpler methods, including manual occlusion of the patient's nose and mouth and neck flexion without head extension also facilitated ventilation via the MT. Even when uncuffed 4-mm ID devices are the only kits available in emergency situations, upper airway resistance can be increased; therefore, such devices should be considered for use without hesitation.

Our technique occasionally yielded insufficient ventilatory volume, especially in earlier cases in this report; however, this was minimized by refinement of BB status. Another concern with our technique is avoiding a high inspiratory oxygen fraction, since we cannot completely exclude the possibility of igniting the BB with electrocautery when a massive leak of oxygenenriched air is present. ${ }^{25}$ A leak could also cause work environment pollution when inhalational anesthetics are used. Off-label use of the BB for this purpose remains the responsibility of the clinician. Further clinical experience and multicentre validation is needed to confirm the efficacy and safety of our technique.

In conclusion, the present airway strategy for pharyngeal ESD provided effective ventilation, easy endoscopic access, and postoperative airway patency without the need for tracheostomy or prolonged intubation. Avoidance of adverse outcomes associated with standard tracheostomy, including speech or swallowing disturbances, possible delayed closure of the stoma or compromised cosmetic outcomes are meaningful to establish restorative and less invasive therapy for pharyngeal cancer.

Acknowledgements We are grateful to Yoshihiro Yamada, Satoko Goto, Arata Yamada, Yuko Shimura, and Kozue Iwamoto for intraoperative assistance with this study.

Funding Internal departmental funding.

Conflicts of interest None declared.

\section{References}

1. Shimizu Y, Yamamoto J, Kato M, et al. Endoscopic submucosal dissection for treatment of early stage hypopharyngeal carcinoma. Gastrointest Endosc 2006; 64: 255-9.

2. Suzuki T, Minami H, Komatsu T, et al. Prolonged carbon dioxide insufflation under general anesthesia for endoscopic submucosal dissection. Endoscopy 2010; 42: 1021-9.

3. Goldsmith T. Evaluation and treatment of swallowing disorders following endotracheal intubation and tracheostomy. Int Anesthesiol Clin 2000; 38: 219-42.

4. Grant N, Davison SP. Management of the post-tracheostomy scar. Laryngoscope 2007; 117: 2107-9.

5. Nomori H, Horio H, Suemasu K. Pressure-controlled ventilation via a minitracheostomy tube: experimental study using a mechanical lung model. Surg Today 2001; 31: 780-4.

6. Craven $R M$, Vanner $R G$. Ventilation of a model lung using various cricothyrotomy devices. Anaesthesia 2004; 59: 595-9.

7. Michalek-Sauberer A, Granegger M, Gilly $H$. The efficacy of spontaneous and controlled ventilation with various cricothyrotomy devices: a quantitative in vitro assessment in a model lung. J Trauma 2011; 71: 886-92.

8. Iizuka T, Kikuchi D, Hoteya S, Yahagi N, Takeda H. Endoscopic submucosal dissection for treatment of mesopharyngeal and hypopharyngeal carcinomas. Endoscopy 2009; 41: 113-7.

9. Venkataraju A, Rozario C, Saravanan P. Accidental fracture of the tip of the Coopdech bronchial blocker during insertion for one lung ventilation. Can J Anesth 2010; 57: 350-4.

10. Ferlay J, Shin HR, Bray F, Forman D, Mathers C, Parkin DM. Estimates of worldwide burden of cancer in 2008: GLOBOCAN 2008. Int J Cancer 2010; 127: 2893-917.

11. Muto M, Minashi K, Yano T, et al. Early detection of superficial squamous cell carcinoma in the head and neck region and 
esophagus by narrow band imaging: a multicenter randomized controlled trial. J Clin Oncol 2010; 28: 1566-72.

12. Iizuka T, Kikuchi D, Hoteya $S$, Takeda H, Kaise $M$. A new technique for pharyngeal endoscopic submucosal dissection: peroral countertraction (with video). Gastrointest Endosc 2012; 76: 1034-8.

13. Kuwabara T, Hiyama T, Oka S, et al. Clinical features of pharyngeal intraepithelial neoplasias and outcomes of treatment by endoscopic submucosal dissection. Gastrointest Endosc 2012; 76: 1095-103.

14. Okada K, Tsuchida T, Ishiyama A, et al. Endoscopic mucosal resection and endoscopic submucosal dissection for en bloc resection of superficial pharyngeal carcinomas. Endoscopy 2012; 44: 556-64.

15. Wright CD. Minitracheostomy. Clin Chest Med 2003; 24: 431-5.

16. Heard AM, Green RJ, Eakins $P$. The formulation and introduction of a 'can't intubate, can't ventilate' algorithm into clinical practice. Anaesthesia 2009; 64: 601-8.

17. Murphy C, Rooney SJ, Maharaj CH, Laffey JG, Harte BH. Comparison of three cuffed emergency percutaneous cricothyroidotomy devices to conventional surgical cricothyroidotomy in a porcine model. Br J Anaesth 2011; 106: 57-64.

18. Metterlein T, Frommer M, Ginzkey $C$, et al. A randomized trial comparing two cuffed emergency cricothyrotomy devices using a wire-guided and a catheter-over-needle technique. J Emerg Med 2011; 41: 326-32.

19. Salah N, El Saigh I, Hayes N, McCaul C. Airway injury during emergency transcutaneous airway access: a comparison at cricothyroid and tracheal sites. Anesth Analg 2009; 109: 1901-7.

20. Salah $N$, Mhuircheartaigh $R N$, Hayes $N$, McCaul $C$. $A$ comparison of four techniques of emergency transcricoid oxygenation in a manikin. Anesth Analg 2010; 110: 1083-5.

21. Martin DG, Kong KL, Lewis GT. Resistance to airflow in anaesthetic breathing systems. Br J Anaesth 1989; 62: 456-61.

22. Wong DT, Kumar A, Prabhu A. The laryngeal mask airway prevents supraglottic leak during ventilation through an uncuffed cricothyroidotomy. Can J Anesth 2007; 54: 151-4.

23. Inoue $S$, Abe $R$, Kawaguchi $M$, Kawano $Y$, Furuya $H$. Use of a laryngeal mask airway to stop a supraglottic air leak which prevented adequate ventilation via a tracheostomy in a patient with cerebral palsy and pneumonia. J Anesth 2011; 25: 415-7.

24. Kei J, Dohrenwend PB. Case report: dealing with a ventilation complication after successful cricothyrotomy. J Emerg Med 2013; 44: 936-8.

25. Simpson JI, Wolf GL. Endotracheal tube fire ignited by pharyngeal electrocautery. Anesthesiology 1986; 65: 76-7. 